\title{
The impact of the 'hub and spoke' model of care for lung cancer and equitable access to surgery
}

\author{
Aamir Khakwani, ${ }^{1}$ Anna L Rich, ${ }^{2}$ Helen A Powell, ${ }^{1,3}$ Laila J Tata, ${ }^{1}$ \\ Rosamund A Stanley, ${ }^{4}$ David R Baldwin, ${ }^{2}$ John P Duffy, ${ }^{5}$ Richard B Hubbard ${ }^{1,3}$
}

\begin{abstract}
- Additional material is published online only. To view please visit the journal online (http://dx.doi.org/10.1136/ thoraxjnl-2014-205841).
\end{abstract}

For numbered affiliations see end of article.

\section{Correspondence to} Dr Aamir Khakwani, Division of Epidemiology and Public Health, University of Nottingham, Nottingham NG5 1PB, UK; aamir.khakwani@ nottingham.ac.uk

Received 5 June 2014 Revised 4 August 2014 Accepted 14 August 2014 Published Online First 2 September 2014

\section{SLinked}

- http://dx.doi.org/10.1136/ thoraxjnl-2014-205517

- http://dx.doi.org/10.1136/ thoraxjnl-2014-205554

- http://dx.doi.org/10.1136/ thoraxjnl-2014-205692

- http://dx.doi.org/10.1136/

thoraxjnl-2014-206153

CrossMark

To cite: Khakwani $A$, Rich $A \mathrm{~L}$, Powell HA, et al. Thorax 2015;70:146-151.

\section{ABSTRACT}

Objectives To determine the influence of where a patient is first seen (either surgical or non-surgical centre) and patient features on having surgery for nonsmall cell lung cancer (NSCLC).

Design Cross-sectional study from individual patients, between 1January 2008 and 31March 2012.

Setting Linked National Lung Cancer Audit and Hospital Episode Statistics datasets.

Participants 95818 English patients with a diagnosis of NSCLC, of whom 12759 (13\%) underwent surgical resection.

Main outcome measure Odds of having surgery based on the empirical catchment population of the 30 thoracic surgical centres in England and whether the patient is first seen in a surgical centre or a non-surgical centre.

Results Patients were more likely to be operated on if they were first seen at a surgical centre (OR 1.37; 95\% $\mathrm{Cl} 1.29$ to 1.45). This was most marked for surgical centres with the largest catchment populations. In these surgical centres with large catchment populations, the resection rate for local patients was 18\% and for patients first seen in a non-surgical centre within catchment was $12 \%$.

Conclusions Surgical centres that serve the largest catchment populations have high resection rates for patients first seen in their own centre but, in contrast, low resection rates for patients first seen at the surrounding centres they serve. Our findings demonstrate the importance of going further than relating resection rates to hospital volume or surgeon number, and show that there is a pressing need to design lung cancer services which enable all patients, including those first seen at non-surgical centres, to have equal access to lung cancer surgery.

\section{INTRODUCTION}

Non-small cell lung cancer (NSCLC) accounts for almost $85 \%$ of all lung cancer cases diagnosed in England, ${ }^{12}$ and for these people surgical resection offers the best chance for cure and long-term survival. $^{3} \quad 4$ England has poor overall survival and lower resection rates when compared with other European countries and North America. ${ }^{5}$ Patients with stage I or II disease, who are a minority of those diagnosed, are believed to benefit from surgical resection. ${ }^{4}$ In a previous study, we have shown that patients first seen at a surgical centre were more likely to have surgery than patients who were not first seen in a surgical centre. ${ }^{3}$ In addition,

\section{Key messages}

What is the key question?

- Is the variation in surgical resection rates for non-small cell lung cancer based on where the patient is first seen and the catchment population of surgical centres in England?

\section{What is the bottom line?}

- The likelihood of having surgery is independently influenced by patient features and where the patient is first seen (either a surgical or non-surgical centre), and a strong association exists between the size of a surgical centre catchment population and which patients had surgery.

\section{Why read on?}

- Findings suggest that there is a need to redesign lung cancer services to allow more patients not first seen in a surgical centre to have equal access to surgery.

patients have a better survival if their operation is in a high-volume surgical centre. ${ }^{1}$

The National Lung Cancer Audit (NLCA) commissioned by the Healthcare Quality Improvement Partnership was established in 2004 to measure the quality of services provided by National Health Service (NHS) hospitals to patients with lung cancer to improve outcomes. ${ }^{3} 4$ There are 157 NHS centres, of which 30 centres offer thoracic surgery and have a thoracic or cardiothoracic surgeon onsite. Almost all patients with lung cancer are discussed by the multidisciplinary team (MDT) at each centre where they are first seen, with thoracic surgeons attending in person or via video conferencing from the 30 centres where thoracic surgical operations are performed (hereafter referred to as 'surgical centres'). Thus, a surgical centre's catchment population is considerably larger than that of an individual NHS centre and it is possible that the size of this catchment population and the lung cancer burden that comes with it could influence access to surgery. To date, there have been no studies quantifying the catchment population or assessing whether the size of the 'lung cancer catchment population' is related to an individual patient's likelihood of having surgery. 
We used data from the NLCA database linked with the Hospital Episode Statistics (HES) inpatient data from 2008 to 2012 to quantify the impact of individual patient features and size of surgical centre lung cancer catchment population on the likelihood of having surgery for NSCLC.

\section{METHODS}

\section{Database}

The validated NLCA database ${ }^{8}$ is a longitudinal database started in 2004 by the Royal College of Physicians, which consists of anonymised records of individuals with a diagnosis of lung cancer collected via the 157 NHS centres in England. The NLCA database currently holds records for over 225000 patients, with approximately 40000 added in 2011 . The ascertainment of cases and data completeness has improved considerably from 2008 onwards. ${ }^{9}$ The NLCA has been linked with the HES inpatient data and Office for National Statistics to enhance the available data and provide date of death.

\section{Study population}

We conducted a cross-sectional analysis and used data on all patients in the NLCA who were first diagnosed in England between 1January 2008 and 31March 2012 and had proven or presumed NSCLC. Patients who were diagnosed through their death certificate were excluded from further analyses as were patients with small cell lung cancer, mesothelioma or carcinoid tumours. In line with the methods used by the NLCA to define lung cancer type, we identified cases of pathologically confirmed NSCLC based on the recorded Systematised Nomenclature of Medicine (SNOMED) codes, whereas cases without a pathologically confirmed diagnosis or 'unknown lung cancer' SNOMED code were also classified as NSCLC; this is in line with the standard NLCA definition of NSCLC. ${ }^{9} 10$

\section{Covariates}

Age at diagnosis, sex, socioeconomic status and source of referral to the MDT were identified from the NLCA. Performance status (PS) was classified according to the WHO definition and stage of the disease was defined using the Union for International Cancer Control definition, both are recorded in the NLCA. We used the HES database to calculate a composite score of comorbidity (the Charlson Comorbidity Index) and to obtain information on ethnicity. We used Office of Population Censuses and Survey Classification of Intervention (OPCS-4) codes in the HES database to identify procedures consistent with potentially curative surgery for NSCLC as has been described previously. ${ }^{41}$ In addition, we included patients who had evidence of having surgery in NLCA database only (1\% additional patients).

\section{Surgical centre lung cancer catchment population}

In England, people with lung cancer are operated on at one of the 30 thoracic surgical centres, which have thoracic or cardiothoracic surgeons on-site, who perform all lung cancer resections. To calculate a catchment population representing the total number of patients with lung cancer that a surgical centre is responsible for, we used data on the distribution of surgically resected patients between surgical centres and the total number of patients with lung cancer first seen at each of the 157 centres. For 128 centres (80\%), all of their resected patients were operated on at a single surgical centre and so all patients with lung cancer (whether they had surgery or not) from these centres were allocated to the catchment population of that surgical centre. Where a centre had patients who were operated on at more than one surgical centre, their total number of patients with lung cancer were allocated to each of these centres' catchment population in the same ratio as the operated patients. Using this method, all the patients with NSCLC, including the non-operated patients, were allocated to the catchment population of one of the 30 surgical centres in England to derive a lung cancer catchment population.

The annual lung cancer patient catchment population for each surgical centre was calculated and categorised as follows: $<400$ patients/year (seven centres), 400 to 700 patients/year (seven centres), 700 to 1100 patients/year (nine centres) and $>1100$ patients/year (seven centres). This division of the surgical centres was done to create quartiles with almost equal number of surgical centres. We also collected data on the number of surgeons working in each surgical centre in 2010 through an online questionnaire sent to the members of Society for Cardiothoracic Surgeons. The information collected via this questionnaire only reflect the number of cardiothoracic surgeons on-site, and it does not reflect the number of whole time equivalent surgeons nor their level of involvement in lung cancer surgery.

\section{Statistical analysis}

All data and statistical management were performed using Stata V.12 (StataCorp). We used multivariate logistic regression analyses to estimate the odds of having surgery (ORs) by patient and surgical centre features. We also performed a sensitivity analysis by restricting our dataset to patients with stage I and II NSCLC.

We used logistic regression analyses to estimate odds of having surgery for patients first seen in a surgical centre versus patients first seen in a non-surgical centre. We looked for interaction between where the patient was first seen and the surgical centre lung cancer catchment population.

Pearson correlation analysis was used to quantify the relationship between the surgical centre catchment population and number of surgeons on-site.

\section{RESULTS}

Our dataset consisted of 120050 patients who were diagnosed with lung cancer between 1January 2008 and 31March 2012. We excluded 20398 (17\%) patients who were diagnosed as having small cell lung cancer, mesothelioma or carcinoid tumours and $554(0.4 \%)$ patients for whom we could not generate a start date. We excluded a further 2555 (2\%) patients who did not have information on centre of diagnosis (or centre of surgery if they had a surgical resection) and $725(0.6 \%)$ patients who could not be redistributed to one of the 30 surgical centres due to miscoding. Therefore, our analysis was based on 95818 patients. The median age at diagnosis was 72 years (IQR 64-79), $64 \%(n=54074)$ of the patients were men, $42 \%(n=40302)$ were categorised as PS 0 or 1 and $41 \%(n=39505)$ had stage IV disease. Thirteen per cent $(n=12759)$ of our cohort had a record of surgery in either HES or NLCA.

Table 1 presents an overview of the unadjusted and adjusted ORs of having surgery by patient features. A lower proportion of men had surgery compared with women (adjusted OR 0.94; $95 \%$ CI 0.89 to 0.98 ). Increasing age, worsening PS and advanced stage disease were all associated with reduced odds of having surgery ( $p$ values $<0.001$ ), whereas patients referred from the emergency department had the lowest odds of having surgery compared with referral from a general practioner. There was evidence that patients from the least affluent areas were less likely to have surgery $\left(\chi^{2} \mathrm{p}\right.$ value for trends $\left.<0.001\right)$. 
Table 1 Result of logistic regression analysis evaluating the association between patient feature and likelihood of having surgery ( $\mathrm{n}=95818$ )

\begin{tabular}{|c|c|c|c|c|c|}
\hline & No. of patients (\%) & No. of patients with surgery (\%) & Unadjusted OR $(95 \% \mathrm{Cl})$ & Adjusted OR $(95 \% \mathrm{Cl})^{*}$ & $\chi^{2} p$ value for trends \\
\hline \multicolumn{6}{|l|}{ Sex } \\
\hline Female & 41744 (43.57) & $5833(13.97)$ & 1 & 1 & \\
\hline Male & $54074(56.43)$ & $6926(12.81)$ & 0.90 (0.87 to 0.93 ) & 0.94 (0.89 to 0.98 ) & $0.018 \dagger$ \\
\hline \multicolumn{6}{|l|}{ Age } \\
\hline$<54$ & $5937(6.20)$ & $1049(17.67)$ & 1 & 1 & \\
\hline $55-59$ & $6282(6.56)$ & $1134(18.05)$ & $1.02(0.93$ to 1.12$)$ & 1.01 (0.89 to 1.14 ) & \\
\hline $60-64$ & $11220(11.71)$ & 2066 (18.41) & 1.05 (0.96 to 1.14$)$ & 0.91 (0.81 to 1.01 ) & \\
\hline $65-69$ & $14179(14.80)$ & $2614(18.44)$ & 1.05 (0.97 to 1.13$)$ & 0.92 (0.83 to 1.02$)$ & \\
\hline $70-74$ & $16560(17.28)$ & $2689(16.24)$ & 0.90 (0.83 to 0.97$)$ & 0.77 (0.69 to 0.85$)$ & \\
\hline $75-79$ & 16806 (17.54) & $2082(12.39)$ & 0.65 (0.60 to 0.71 ) & 0.55 (0.49 to 0.61 ) & \\
\hline $80-84$ & 14073 (14.69) & $940(6.68)$ & 0.33 (0.30 to 0.36$)$ & 0.25 (0.22 to 0.28$)$ & \\
\hline $85+$ & $10761(11.23)$ & $185(1.72)$ & 0.08 (0.06 to 0.09$)$ & 0.06 (0.05 to 0.08$)$ & $<0.001$ \\
\hline \multicolumn{6}{|l|}{ Stage } \\
\hline$I A-I B$ & $11284(11.78)$ & $6189(54.85)$ & 1 & 1 & \\
\hline$\|A-\| B$ & $5686(5.93)$ & $2392(42.07)$ & 0.59 (0.56 to 0.63$)$ & 0.54 (0.50 to 0.58 ) & \\
\hline IIIA & $9249(9.65)$ & 1448 (15.66) & 0.15 (0.14 to 0.16$)$ & 0.10 (0.09 to 0.11$)$ & \\
\hline IIIB & $11697(12.21)$ & $474(4.05)$ & 0.03 (0.03 to 0.04$)$ & 0.02 (0.02 to 0.03 ) & \\
\hline IV & $39505(41.23)$ & $599(1.52)$ & 0.01 (0.01 to 0.02 ) & 0.01 (0.01 to 0.01 ) & $<0.001$ \\
\hline Missing & $18397(19.20)$ & 1657 (9.01) & 0.08 (0.07 to 0.08 ) & 0.07 (0.07 to 0.08 ) & \\
\hline \multicolumn{6}{|l|}{ Performance status } \\
\hline 0 & 15357 (16.03) & $5245(34.15)$ & 1 & 1 & \\
\hline 1 & $24945(26.03)$ & 4461 (17.88) & 0.41 (0.40 to 0.43 ) & 0.49 (0.46 to 0.52 ) & \\
\hline 2 & 16368 (17.08) & $769(4.70)$ & 0.09 (0.08 to 0.10$)$ & 0.12 (0.11 to 0.14 ) & \\
\hline 3 & 15377 (16.05) & $138(0.90)$ & 0.01 (0.01 to 0.02 ) & 0.03 (0.02 to 0.03 ) & \\
\hline 4 & 5168 (5.39) & $16(0.31)$ & 0.01 (0.01 to 0.01 ) & 0.02 (0.01 to 0.03 ) & $<0.001$ \\
\hline Missing & $18603(19.41)$ & $2130(11.45)$ & 0.24 (0.23 to 0.26 ) & 0.36 (0.34 to 0.39 ) & \\
\hline \multicolumn{6}{|l|}{ Ethnicity } \\
\hline Caucasian & $60396(63.03)$ & $8173(13.53)$ & 1 & 1 & \\
\hline Black patients & $683(0.71)$ & $98(14.35)$ & 1.07 (0.86 to 1.32 ) & 1.15 (0.86 to 1.53 ) & \\
\hline Asian & $827(0.86)$ & $120(14.51)$ & 1.08 (0.89 to 1.31 ) & 1.10 (0.85 to 1.43 ) & \\
\hline Mixed & $107(0.11)$ & 17 (15.89) & 1.20 (0.71 to 2.02 ) & 0.97 (0.48 to 1.94 ) & \\
\hline Others & $737(0.77)$ & $100(13.57)$ & 1.00 (0.81 to 1.24 ) & 1.15 (0.87 to 1.53 ) & \\
\hline Missing & 33068 (34.51) & $4251(12.86)$ & 0.94 (0.90 to 0.98 ) & 0.93 (0.89 to 0.99 ) & $0.435 t$ \\
\hline \multicolumn{6}{|l|}{ Townsend quintile } \\
\hline 1 (most affluent) & 14975 (15.63) & $2158(14.41)$ & 1 & 1 & \\
\hline 2 & 17837 (18.62) & $2444(13.70)$ & 0.94 (0.88 to 1.00$)$ & 0.89 (0.82 to 0.97 ) & \\
\hline 3 & 18839 (19.66) & $2492(13.23)$ & 0.90 (0.85 to 0.96 ) & 0.84 (0.78 to 0.92 ) & \\
\hline 4 & $20332(21.22)$ & $2645(13.01)$ & 0.88 (0.83 to 0.94 ) & 0.83 (0.76 to 0.90$)$ & \\
\hline 5 & $21966(22.92)$ & 2935 (13.36) & 0.91 (0.86 to 0.97 ) & 0.80 (0.74 to 0.87 ) & $<0.001$ \\
\hline Missing & 1869 (1.95) & $85(4.55)$ & 0.28 (0.22 to 0.35$)$ & 0.44 (0.34 to 0.58 ) & \\
\hline \multicolumn{6}{|l|}{ Charlson Index } \\
\hline 0 & $29509(30.80)$ & $4830(16.37)$ & 1 & 1 & \\
\hline 1 & 19001 (19.83) & $3292(17.33)$ & 1.07 (1.01 to 1.12 ) & 1.01 (0.95 to 1.08 ) & \\
\hline $2-3$ & 17418 (18.18) & 2721 (15.62) & 0.94 (0.89 to 0.99 ) & 0.99 (0.95 to 1.06$)$ & \\
\hline $4+$ & 29890 (31.19) & 1916 (6.41) & 0.34 (0.33 to 0.36 ) & 0.78 (0.73 to 0.84 ) & 0.003 \\
\hline \multicolumn{6}{|l|}{ Source of referral } \\
\hline Referral from GP & $45465(47.45)$ & 7167 (15.76) & 1 & 1 & \\
\hline Emergency adm. & 11991 (12.51) & $480(4.00)$ & 0.22 (0.20 to 0.24 ) & 0.54 (0.48 to 0.60$)$ & \\
\hline Ref. from consultant & $20137(21.02)$ & 3295 (16.36) & 1.04 (0.99 to 1.09 ) & 1.12 (1.05 to 1.19$)$ & \\
\hline Other sources & $16115(16.82)$ & 1564 (9.71) & 0.57 (0.54 to 0.60$)$ & 0.87 (0.81 to 0.94 ) & $<0.001 \dagger$ \\
\hline Missing & $2110(2.20)$ & 253 (11.99) & 0.72 (0.63 to 0.83 ) & 0.85 (0.72 to 1.01$)$ & \\
\hline
\end{tabular}

${ }^{*}$ Odd ratio adjusted for every other variable in the table. + Log likelihood ratio test. GP, general practioner.

\section{Surgical centre catchment population for patients with lung} cancer

\section{Basic description}

The seven surgical centres with the smallest lung cancer catchment populations covered only $8 \%$ of the national burden of patients with lung cancer (table 2); however, in these centres the proportion of patients resected was slightly higher (14.8\%) than that in the centres with larger lung cancer catchment populations $(12.3 \%, 13.5 \%$ and $13.2 \%$, respectively) and this difference was on the borderline of statistical significance 
Table 2 Result of logistic regression analysis evaluating the association between centre feature and likelihood of having surgery ( $\mathrm{n}=95818$ )

\begin{tabular}{|c|c|c|c|c|c|}
\hline & No. of patients (\%) & $\begin{array}{l}\text { No. of patients } \\
\text { with surgery (\%) }\end{array}$ & Unadjusted OR (95\% Cl) & $\begin{array}{l}\text { Adjusted OR } \\
(95 \% \mathrm{Cl})^{*}\end{array}$ & $\begin{array}{l}\chi^{2} p \text { value log-likelihood } \\
\text { ratio test }\end{array}$ \\
\hline \multicolumn{6}{|c|}{ Surgical centre annual catchment population } \\
\hline$<400$ & $7566(8)$ & $1122(15)$ & 1 & 1 & \\
\hline $400-700$ & $15581(16)$ & $1929(12)$ & $0.81(0.74$ to 0.87$)$ & 0.87 (0.78 to 0.97$)$ & \\
\hline $700-1100$ & $33009(34)$ & $4464(14)$ & $0.89(0.83$ to 0.96$)$ & 0.87 (0.79 to 0.95$)$ & \\
\hline$>1100$ & $39662(41)$ & $5244(13)$ & 0.87 (0.81 to 0.93$)$ & $0.88(0.80$ to 0.96$)$ & 0.06 \\
\hline \multicolumn{6}{|c|}{ No. of cardiothoracic surgeons on-site } \\
\hline$\leq 3$ surgeons & $26493(28)$ & $3517(13)$ & 1 & 1 & \\
\hline$>3-\leq 5$ surgeons & $51579(64)$ & $8095(13)$ & $0.98(0.94$ to 1.03$)$ & $0.99(0.93$ to 1.05$)$ & \\
\hline$>5$ surgeons & 7746 (8) & $1147(15)$ & $1.13(1.05$ to 1.22$)$ & $0.99(0.90$ to 1.09$)$ & 0.88 \\
\hline
\end{tabular}

(log-likelihood $\mathrm{p}$ value $=0.06)$. In the smallest lung cancer catchment population group, $59 \%$ of patients were first seen in a surgical centre compared with only $15 \%$ in the largest lung cancer catchment population group. When adjusted for patient features, the likelihood of having surgery was marginally lower for people in larger lung cancer catchment populations (OR 0.87, 0.87 and 0.88 ) compared with those in the smallest catchment populations.

Figure 1 represents the correlation between surgical centre lung cancer catchment population and number of surgeons and shows a moderate positive correlation between increasing catchment population and number of surgeons (Pearson's correlation coefficient $=0.46 \quad(95 \%$ CI 0.45 to 0.46$))$. All the surgical centres with the smallest lung cancer catchment population had three or fewer surgeons on-site, whereas only one of the seven surgical centres with the largest lung cancer catchment population had more than five surgeons on-site. There was also no association seen between the number of cardiothoracic surgeons on-site and the likelihood of having surgery ( $p$ value $=0.88)$.

Resection in patients first seen at a surgical centre compared with those first seen at a non-surgical centre

We divided patients into those who were first seen and managed by a surgical centre and patients who were first seen in nonsurgical centres. Table 3 lists the proportions and the adjusted ORs of having surgery stratified by lung cancer catchment population. Overall, only $25 \%$ of the people with lung cancer were

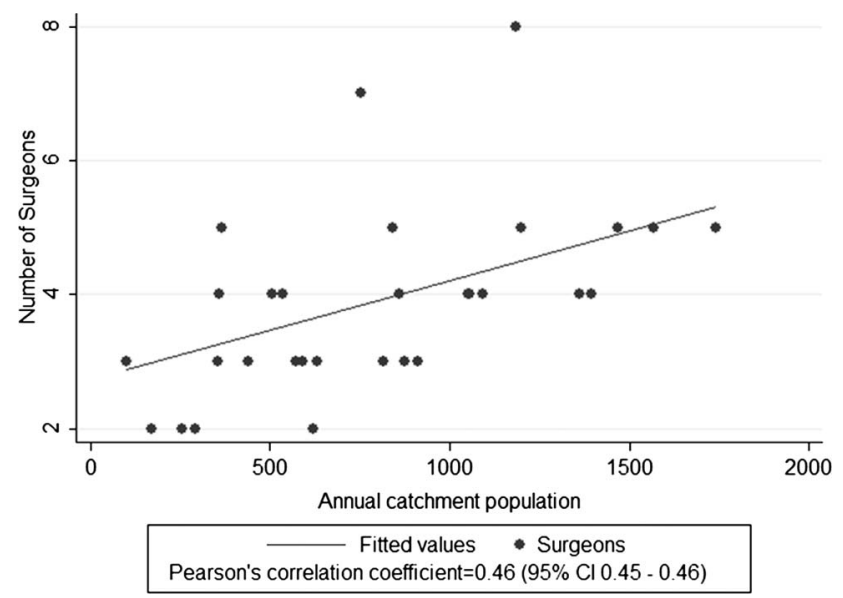

Figure 1 Number of cardiothoracic surgeons by annual surgical centre lung cancer catchment population. first seen in a surgical centre and when adjusted for patient features, the odds of having surgery for these patients was $35 \%$ higher compared with patients first seen in a non-surgical centre (OR 1.35 ; 95\% CI 1.27 to 1.43 ; ie, $17 \%$ versus $12 \%$; table 3 ). In the univariate analysis (data not shown), patient features most strongly associated with stage of the disease and PS. The proportions of surgical centre versus non-surgical centre patients in the smallest catchment populations were similar (59\% versus $41 \%)$, but this difference increased to almost 1:6 (15\% versus $85 \%)$ in the largest catchment populations. For surgical centres with a smaller catchment population size, there was no difference in the odds of having surgery between patients first seen in a surgical centre and patients first seen in the non-surgical centre (OR 0.98 ; $95 \%$ CI 0.80 to 1.20 ). While in surgical centres with a large catchment population size, patients first seen in a surgical centre were $57 \%$ more likely to have surgery compared with patients first seen in a non-surgical centre (OR 1.57; 95\% CI 1.41 to 1.74 ).

Surgical centres with a large catchment population were observed to have a higher resection rate on patients first seen in their own centre, compared with those patients first seen in a non-surgical centre in the surrounding area, and served by the same surgical centre (figure 2).

\section{Sensitivity analysis for stages I and II}

We performed similar analyses on patients with early stage disease (ie, stage IA-IB $(n=11284)$ and IIA-IIB $(n=5686)$ ). Online supplementary table 1 presents the multivariate logistic regression analyses and the results show that the association between likelihood of having surgery and surgical centre lung cancer catchment population is more pronounced in patients with stage IA-IB ( $\mathrm{p}$ value for trends $<0.001$ ) compared with the whole cohort and there is no significant association within the subgroup with stage IIA-IIB disease. In both groups, there was a higher proportion of patients resected in surgical centres with the smallest catchment size (62\% stage I and $45 \%$ stage II) compared with surgical centres with the largest catchment size (53\% stage I and 39\% stage II).

\section{DISCUSSION}

Our results demonstrate that the likelihood of having surgery for patients with NSCLC is independently influenced by patient features including age, sex, stage, PS and comorbidity which are all part of clinically appropriate case selection. The likelihood of having surgery is also influenced by surgical centre features, most notably the surgical centre lung cancer catchment population. It was observed that as the lung cancer catchment 
Table 3 Odds of having surgery for non-surgical centre patients and surgical centre patients by surgical centre catchment population $(\mathrm{n}=95$ 818)

\begin{tabular}{|c|c|c|c|c|c|c|}
\hline \multirow[b]{2}{*}{$\begin{array}{l}\text { Surgical centre lung cancer } \\
\text { catchment population }(\mathrm{n})\end{array}$} & \multicolumn{2}{|c|}{$\begin{array}{l}\text { Patients first seen in a non-surgical } \\
\text { centre }(n=71777)\end{array}$} & \multicolumn{2}{|c|}{$\begin{array}{l}\text { Patients first seen in a surgical centre } \\
(n=24041)\end{array}$} & \multirow[b]{2}{*}{$\begin{array}{l}\text { Unadjusted OR } \\
(95 \% \mathrm{CI})\end{array}$} & \multirow[b]{2}{*}{$\begin{array}{l}\text { Adjusted OR } \\
(95 \% \mathrm{Cl}) \neq \S\end{array}$} \\
\hline & $\begin{array}{l}\text { No. of patients } \\
(\%)\end{array}$ & $\begin{array}{l}\text { No. of patients with } \\
\text { surgery }(\%)\end{array}$ & $\begin{array}{l}\text { No. of } \\
\text { patients (\%) }\end{array}$ & $\begin{array}{l}\text { No. of patients with } \\
\text { surgery }(\%)\end{array}$ & & \\
\hline$<400$ & $3122(41)$ & $414(13)$ & 4444 (59) & 708 (16) & $1.23(1.08$ to 1.41$)$ & $0.98(0.80$ to 1.20$)$ \\
\hline $400-700$ & $11392(73)$ & $1344(12)$ & 4189 (27) & $585(14)$ & $1.21(1.09$ to 1.34$)$ & $1.02(0.88$ to 1.18$)$ \\
\hline $700-1100$ & $23564(71)$ & $2820(12)$ & $9445(29)$ & $1644(17)$ & 1.55 (1.45 to 1.65$)$ & $1.46(1.33$ to 1.61$)$ \\
\hline$>1100$ & 33699 (85) & $4161(12)$ & $5963(15)$ & $1083(18)$ & 1.57 (1.46 to 1.69$)$ & $1.52(1.37$ to 1.68$)$ \\
\hline Overall & $71777(75)$ & $8739(12)$ & $24041(25)$ & 4020 (17) & 1.44 (1.39 to 1.50$)$ & 1.35 (1.27 to 1.43$)$ \\
\hline
\end{tabular}

¥Adjusted for age, sex, performance status, stage, comorbidity, ethnicity, source of referral, socioeconomic status and number of cardiothoracic surgeons.

$\S$ Comparison between patients first seen at a surgical centre and those first seen at a non-surgical centre within the same group of lung cancer catchment population.

population of surgical centres increases, the centre is more likely to operate on patients first seen in house and less likely to operate on patients first seen at the non-surgical centres, even though this group of patients represents $75 \%$ of the total lung cancer population overall and $85 \%$ of the patients for the centres with the large catchment population size. The same association was seen when we restricted our analyses to histologically proven cases only (data not shown).

\section{Strengths and limitations}

This study uses a large dataset and its representative nature gives a true reflection of the diagnosis, treatment and management of patients with NSCLC in England. Although the data entry into the NLCA is non-mandatory, previous studies have shown that the missing data are unbiased. ${ }^{4}$ As an added measure, for this study, we used only data from 2008 onwards, when the NLCA case ascertainment achieved a level of more than $90 \%{ }^{9}{ }^{10}$ Unlike studies that use large cancer registry data, ${ }^{5} 1213$ our linked dataset provides more information on comorbidity and PS allowing for better case-mix adjustment. We used a valid measure of comorbidity, the Charlson Index using the HES database which has shown coding accuracy of $91 \% .{ }^{14}$ The linked HES and NLCA database also allowed us to identify about $4 \%$ more surgically resected patients which would have been missed using the NLCA data alone. ${ }^{15}$

We used strict criteria to identify patients who had complete data on surgical centre and excluded 2500 patients who had surgery but incomplete accompanying data, that is, missing data on centre first seen or centre where patient had surgery. It is unlikely that these exclusions will have introduced bias as we have no reason to suspect that any one surgical centre had more missing data than the others. We used number of cardiothoracic surgeons for 2010 only, but this is likely to be representative as it falls in the middle of the timeframe of our patient cohort. It was not possible to distinguish between operations performed by cardiothoracic surgeons compared with pure thoracic surgeons. Previous studies have reported that higher resection rates, better survival and the ability to handle complex operations are associated with specialist thoracic surgeons. ${ }^{16-18}$ In addition, there could be other features of a surgical centre, for example, time to decision (for surgery), MDT composition and the number of lung cancer nurse specialists which may influence the timing of decisions and even patient willingness to undergo surgical resection.

\section{Comparison with other studies}

The findings in this study are in agreement with the observation from previous studies using UK and European databases; women are more likely to have surgery and have a better prognosis compared with men, ${ }^{1}{ }^{2}$ while increasing age, comorbidity, worsening PS and advanced stage disease were all unfavourable factors for having surgery and survival. ${ }^{3} 419$ A previous study using the NLCA database by Rich et $a l^{3}$ showed an increased odds (OR 1.51) of having surgery if the patient is first seen in a surgical centre, which were similar to our study; however, our study is the first to identify odds of having surgery based on the lung cancer catchment population of a surgical centre. In addition, we were also able to show a significant trend association between socioeconomic status and odds of having surgery, mainly due to a more complete dataset than the previous study.
Figure 2 Interaction between likelihood of having surgery and surgical centre catchment population by where the patient is first seen.
Interaction between surgical centre catchment population and likelihood of having surgery

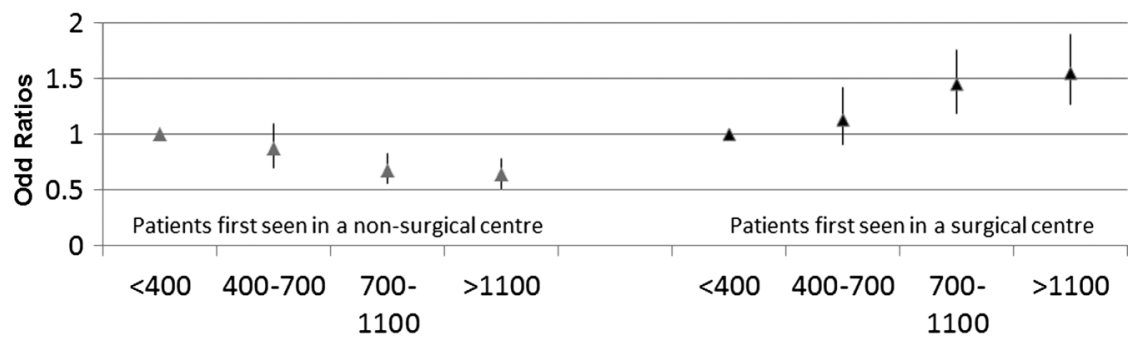

Annual surgical centre catchment population 
Previous studies in the UK have highlighted geographical inequality in diagnosis and treatment based on where the patient is first seen and managed, ${ }^{132021}$ while there are contrasting studies regarding hospital volume and survival. ${ }^{22-24} \mathrm{Lau}$ et $\mathrm{al}^{16}$ showed that increasing the number of cardiothoracic surgeons increased the resection rate of the centre, which is also seen in our study. However, our results would suggest that this increase would preferentially benefit in-house patients rather than patients first seen in a non-surgical centre. Lau et al also found no correlation between resection rates and annual number of NSCLC cases seen in all surgical and non-surgical centres (Pearson's correlation coefficient $=0.0017$ ). However, we believe our results are more accurate as our data are not derived from surgical centres alone.

\section{Clinical relevance}

This study has identified an inequality in lung cancer care provision. Surgical centres with large catchment populations have more surgeons to address the lung cancer burden but are unable to provide equal access to surgery for patients seen at the nonsurgical centres they serve, compared with patients presenting to their own centre. Our study is the first of its kind to look at the catchment population a surgical centre is responsible for and to test the 'hub and spoke' model. Ideally this model, with surgical centres drawing patients from surrounding centres, allows the NHS to accurately redistribute its resources and manpower according to the need to create equality in lung cancer care. Our study has highlighted the key role that the surgical centres with large catchment populations can play in improving the surgical resection rates in England and the need to provide equal access to this service.

\author{
Author affiliations \\ ${ }^{1}$ Division of Epidemiology and Public Health, University of Nottingham, Nottingham, \\ UK \\ ${ }^{2}$ Department of Respiratory Medicine, Nottingham University Hospitals, Nottingham, \\ UK \\ ${ }^{3}$ Nottingham Respiratory Research Unit, University of Nottingham, Nottingham, UK \\ ${ }^{4}$ Falls and Fragility Audit Programme Manager Clinical Effectiveness and Evaluation \\ Unit, Royal College of Physicians, London, UK \\ ${ }^{5}$ Department of Thoracic Surgery, Nottingham University Hospitals, Nottingham, UK
}

Acknowledgements The authors would like to acknowledge the British Lung Foundation who funded AK and RBH, and the NHS Information Centre for Health and Social care (Arthur Yelland and Xanthe Hannah), who provided data. They would also like to thank the wider NLCA steering group (Professor Anne Tattersfield, Dr Catherine Free, Dr Laura Jones, Dr Michael Peake and Dr Paul Beckett).

Contributors The conception of the study was done by RBH, ALR and RAS. AK acquired the data from the HSCIC and all analysis was done by AK. RBH and ALR were involved in the data interpretation. Majority of the paper (including the initial draft) was written by AK. HAP, LJT, RAS, JPD, DRB, ALR and RBH were involved revising the paper critically. This final manuscript was approved by all the authors prior to submission.

Competing interests LJT has conducted the statistical analyses for the National Lung Cancer Audit annual reports for the past 4 years, which was funded by the NHS Information Centre; LT has not received any personal earnings from the NHS $\mathrm{HSCIC}$ for this work. RBH has a grant provided by the British Lung Foundation chair of respiratory epidemiology. RAS was employed by the $\mathrm{HSCIC}$ as the Project Manager for the NLCA database until October 2013. AK is currently doing his PhD from University of Nottingham on a studentship funded by the British Lung Foundation.

Ethics approval The data was obtained from the Healthcare Quality Improvement Partnership (HQIP). Ethical approval from the University of Nottingham medical school research ethnics committee was obtained by the researchers to work on a linked HES and NLCA dataset (RU943 177570-MV6J3). The NLCA has Ethics and Confidentiality Committee (ECC) approval to use patient information from the National Health Services (NHS). Finally for this specific set of work, we also obtained approval from HQIP who commission the audit and HSCIC Caldicott guardian signed off the data sharing agreement (IG Reference: IC381DS). The data were anonymised in the linked dataset by the HSCIC personal prior to be given to the researchers.

Provenance and peer review Not commissioned; externally peer reviewed.

Data sharing statement Data sharing agreement attached (IG Reference IC381DS).

\section{REFERENCES}

1 Luchtenborg M, Riaz SP, Coupland VH, et al. High procedure volume is strongly associated with improved survival after lung cancer surgery. J Clin Oncol 2013;31:3141-6.

2 Riaz SP, Linklater KM, Page $R$, et al. Recent trends in resection rates among non-small cell lung cancer patients in England. Thorax 2012;67:811-14.

3 Rich AL, Tata $L$, Free CM, et al. Inequalities in outcomes for non-small cell lung cancer: the influence of clinical characteristics and features of the local lung cancer service. Thorax 2011;66:1078-84.

4 Khakwani A, Rich AL, Powell HA, et al. Lung cancer survival in England: trends in non-small-cell lung cancer survival over the duration of the National Lung Cancer Audit. Br J Cancer 2013;109:2058-65.

5 Coleman MP, Forman D, Bryant H, et al. Cancer survival in Australia, Canada, Denmark, Norway, Sweden, and the UK, 1995-2007 (the International Cancer Benchmarking Partnership): an analysis of population-based cancer registry data. Lancet 2011;377:127-38.

6 Holmberg L, Sandin F, Bray F, et al. National comparisons of lung cancer survival in England, Norway and Sweden 2001-2004: differences occur early in follow-up. Thorax 2010;65:436-41.

7 National Institute for Health and Clinical Excellence. Lung cancer: the diagnosis and treatment of lung cancer. [Clinical guideline] April 2011; http://guidance.nice.org.uk/ CG121

8 Rich AL, Tata LJ, Stanley RA, et al. Lung cancer in England: information from the National Lung Cancer Audit (LUCADA). Lung Cancer 2011;72:16-22.

9 Health and Social Care Information Centre. National Lung Cancer Audit 2010. 2010.

10 Health and Social Care Information Centre. National Lung Cancer Audit Report 2011. 2011. http://www.hqip.org.uk/assets/NCAPOP-Library/Lung-Cancer-NHS-IC-AUDIT-2011. pdf

11 Powell HA, Tata LJ, Baldwin DR, et al. Early mortality after surgical resection for lung cancer: an analysis of the English National Lung cancer audit. Thorax 2013;68:826-34.

12 Riaz SP, Luchtenborg M, Jack RH, et al. Variation in surgical resection for lung cancer in relation to survival: population-based study in England 2004-2006. Eur J Cancer 2012;48:54-60.

13 Woolhouse I. Variation in lung cancer outcomes in the UK and Europe. Clin Med 2011;11:110-11.

14 Campbell SE, Campbell MK, Grimshaw JM, et al. A systematic review of discharge coding accuracy. J Public Health Med 2001;23:205-11.

15 Powell H, Tata L, Stanley R, et al. P13ldentifying patients who had surgical resection for non-small cell lung cancer using large datasets. Thorax 2013;68(Suppl 3):A80.

16 Lau KKW, Rathinam S, Waller DA, et al. The effects of increased provision of thoracic surgical specialists on the variation in lung cancer resection rate in England. J Thoracic Oncol 2013;8:68-72.

17 von Meyenfeldt EM, Gooiker GA, van Gijn W, et al. The relationship between volume or surgeon specialty and outcome in the surgical treatment of lung cancer: a systematic review and meta-analysis. J Thorac Oncol 2012;7:1170-8.

18 Treasure T, Utley M, Bailey A. Assessment of whether in-hospital mortality for lobectomy is a useful standard for the quality of lung cancer surgery: retrospective study. BMJ 2003;327:73.

19 Strand TE, Rostad H, Moller B, et al. Survival after resection for primary lung cancer: a population based study of 3211 resected patients. Thorax 2006:61:710-15.

20 Jack RH, Gulliford MC, Ferguson J, et al. Geographical inequalities in lung cancer management and survival in South East England: evidence of variation in access to oncology services? [Erratum appears in Br J Cancer. 2004 Nov 15;91(10):1852]. Br J Cancer 2003;88:1025-31.

21 Khakwani $A$, Rich AL, Tata $L$, et al. The pathological confirmation rate of lung cancer in England using the NLCA database. Lung Cancer 2013;79:125-31.

22 Birkmeyer JD, Siewers AE, Finlayson EVA, et al. Hospital volume and surgical mortality in the United States. N Engl J Med 2002;346:1128-37.

23 Boudourakis LD, Wang TS, Roman SA, et al. Evolution of the surgeon-volume, patient-outcome relationship. [Erratum appears in Ann Surg. 2009 Dec;250 (6):1046]. Ann Surg 2009;250:159-65.

24 Kozower BD, Stukenborg GJ. The relationship between hospital lung cancer resection volume and patient mortality risk. Ann Surg 2011;254:1032-7. 